\title{
The efficacy of course-specific library guides to support essay writing at the University of Cape Town
}

\author{
Maureen Chiware ${ }^{1}$ \\ maureen.chiware@uct.ac.za \\ ORCID ID: orcid.org/0000-0002-8189-9948
}

\begin{abstract}
Received: 25 February 2015
Accepted: 29 March 2015

University of Cape Town Libraries uses the LibGuides platform to create general and subject-specific guides to provide support to its user community. The purpose of this paper is to present results of an evaluation of the use of LibGuides in essay writing for Economics undergraduate students. The evaluation was based on an online survey conducted among students in four courses. Quantitative data was analysed using Microsoft Excel while content analysis was employed on qualitative data. The findings show that targeted essay guides were used more frequently than the general Economics guides. Guide use was concentrated during the period that students were working on their essays. The results indicate a link between library instruction and guide usage. The majority of the students found the guides very helpful. The results also highlight areas that require improvement such as marketing, user-friendliness, as well as accessibility of guides through learning management systems.
\end{abstract}

Keywords: South Africa, LibGuides, subject guides, evaluation, essay writing, academic writing support, economics, library guides to writing

\section{Introduction}

The need for library guides to help students identify academic and scholarly literature for their essays was highlighted by Adebonojo who noted that, with library collections becoming increasingly digital, students who do not know how to use library resources without assistance from librarians tend initially to rush to Google when faced with assignments (Adebonojo 2010: 398). There is a substantial amount of literature on how libraries have been providing guides for library support, delivery of library resources, and training of different user groups. Originally created as printed pathfinders, guides have adopted emerging technologies, evolving into online interactive resources. Some libraries are developing guides in-house (Murphy \& Black 2013; Leighton \& May 2013; Barr 2010) while others use commercial products such as the LibGuides platform (Bowen 2012; Yeo 2011; Quellette 2011; Gonzalez \& Westbrock 2010). The structure and focus of guides vary. Some are broadly focused whilst others are more specific, in the form of research, subject, course or assignment guides.

\section{Use of library guides}

In discussing the use of library guides, some authors have debated the advantages of using subject guides over coursespecific guides. Others have focused on the embedding of guides in learning management systems or the evaluation of guides. All three topics will be illustrated below.

\subsection{Subject guides versus course-specific guides}

Reeb and Gibbons' 2004 paper is cited in most literature on the debate around using general subject guides or coursespecific guides. They noted that students do not think in terms of subject disciplines - that the concept of subject areas is "not usually part of a students' mental model" (Reeb and Gibbons 2004: 125). They therefore argue that by creating guides that are subject focused, librarians create a disconnection between the guides and students. They go on to say that this disconnection has been worsened by the fact that university curricula are increasingly becoming interdisciplinary. As a result, students registered for an interdisciplinary course, for example, often do not know which subject guide is relevant to their course. Reeb and Gibbons concluded that "guides that are organised or delivered at the course level appear to be more in line with how students approach library research" (Reeb and Gibbons 2004: 128). Several other authors agree with Reed and Gibbons that students prefer course or assignment-specific guides rather than subject guides and that more specific guides are used more frequently than subject guides (Leighton \& May 2013; Ouellette 2011; Yeo 2011; Adebonojo 2010; Gonzalez \& Westbrock 2010; Strutin 2008).

A comparison of course and subject guides at Li Ka Shing Library in Singapore found that in four out of five subject areas, the corresponding course guides received more views than the more general subject guides. The difference in the number of page views between subject guides and course guides ranged from $30 \%$ to $450 \%$ (Yeo 2011: 61). In a similar study at New Mexico State University, Gonzalez and Westbrock observed that their course and assignment-specific guides were being accessed much more than the general subject guides. This discovery led them to change their focus 
from creating guides for departments to concentrating on guides for specific courses and assignments. They noted that students will use course or assignment-specific guides as these are relevant to students' immediate needs (Gonzalez \& Westbrock 2010: 649). A major positive outcome of introducing more specific guides was that, as faculty members began to see the benefits of guides tailored to their students' needs, the faculty members became more involved, offering suggestions on what to include or exclude in the guides. In yet another similar study, Leighton and May (2013) concluded that guides are effective when they are targeted to a specific course. They proposed that the effectiveness of a specific guide is further enhanced if instruction on how to use the guide is provided (Leighton \& May 2013: 135).

Contrary to much of the literature, Murphy and Black (2013) challenged the popular assertion that course guides are more useful. They concluded that the value of course guides is discipline-specific. Creating course guides may not be worth the effort in some disciplines such as sciences where "a limited set of discovery tools" is used "making the need for a customized library guide less pronounced” (Murphy \& Black 2013: 533).

Course and assignment-specific guides can be used to support information literacy instruction (Yeo 2011: 63). For example, librarians at New Mexico State University used their specific guides during instruction sessions in place of more generic presentations (Gonzalez \& Westbrock 2010). Having concluded that guides provide an important avenue for teaching users how to use library resources and services effectively, Brazzeal (2006: 366) proposed that guides be structured around library instruction sessions. O'Sullivan and Scott noted the value of in-class demonstration of guides. They reported that the number of students that found their pathfinder useful increased from $62 \%$ to $71 \%$ after an in-class demonstration (2000: 41).

\subsection{Guides in learning management systems}

Learning management systems such as Blackboard and Sakai offer students a learning environment that can be tailored to their needs for specific courses. At the University of Cape Town (UCT), a Sakai-based learning management system (LMS) termed 'Vula' is used. According to Reeb and Gibbon, because of customised learning environments, students' expectations for customised services in the library are raised (2004: 126). In response to the need for customised environments, many librarians are embedding their course and assignment guides in learning management systems. Barr (2010) referred to a number of institutions at which guides are embedded in learning management systems. The value of placing guides in these systems was echoed by Bowen (2012), Gonzalez \& Westbrock (2010) and Yeo (2011). Embedding the guides in a LMS is a way of promoting the use of guides. Barr noted that, with most of their learning material available via learning management systems, students visit the sites regularly. During their frequent visits, chances of students using embedded library guides increase, since no extra effort is required and students "do not have to go elsewhere" (Barr 2010: 296). In addition, students will view a guide that is in a learning management tool "as part of the course" (Yeo 2011: 57). In their set of best practice guidelines, Gonzalez and Westbrock recommended embedding links to guides in course management systems (2010: 656); a study by Murphy and Black (2013: 532) confirmed that guides embedded in learning management systems were helpful to students. Librarians at Harvard's Ernst Mayr and Cabot Libraries created both a generic and a course-specific guide. The generic guide was uploaded campus-wide to provide resources targeted to all science undergraduate students. The course-specific guide was embedded in the individual LMS site for life sciences. Their study highlighted both the importance of creating course-specific guides and making the guides available via learning management systems (Barr 2010).

A number of approaches have been identified in the literature for embedding library content in learning management systems (Bowen 2012: 451). One of these approaches involves placing in the LMS a dedicated link, button or icon through which a guide is accessible. This approach enhances the guide's visibility, which creates a disincentive for students to use Google and, instead, makes library resources central to students' research (2012: 452). Bowen investigated undergraduates' perceptions of a LibGuide embedded in the course management system at California State University. In a survey, a guide was embedded as a button in the left-hand side navigation of the course management system. Clicking on the button took the students to a LibGuides page with library resources. The strong positive responses showed that students perceived the guide as a valuable tool for completing their research assignment. They indicated that a significant part of the value of the guide was its location within the course management system (Bowen 2012: 461).

\subsection{Guide evaluation}

The extent of use and the effectiveness of guides are important to guide owners; many have tried to assess their guides. Gonzalez and Westbrock noted that evaluation of guides is necessary as the information gathered is important for directing librarians to the need either to update current guides or create new ones (2010: 640). They concluded that, as guides require constant maintenance, it is critical to conduct regular evaluations of the guides to monitor quality and usefulness (Gonzalez \& Westbrock 2010: 654). However, they also noted that assessment of guides has always been problematic. The simplest and most widely-used method for assessing guides and for which data is readily available is the tracking of usage statistics which are generated automatically by the system in which the guide is built (2010: 653). A number of authors have utilised usage statistics to assess their guides (Dalton \& Pan 2014; Leighton \& May 2013; Murphy \& Black 2013; Yeo 2011; Adebonojo 2010; Strutin 2008). However, in instances where statistics are used alone, the assessment is limited in that it does not give any feedback on whether students were able to use the guides or whether they found the guides useful. Both Staley (2007: 120) and Ouellette (2011: 437) noted the limited amount of literature focusing on user-centred data. Wakeham et al. (2012) concluded that there was no clear evidence of the usefulness of guides in the literature as librarians were not actively evaluating the use of their guides. However, some 
librarians have tried to assess their guides using surveys: A four-question survey was inserted into all subject guides at the University of Maryland to assess how the guides were being used (Tchangalova \& Feigley 2008). Wakeham et al. (2012) employed a three-question survey on guide use at Anglia Ruskin library. Semi-structured interviews were conducted by Ouellette (2011) at the University of Alberta and Grant MacEwan University. The interviews focused on how students typically find information, and their experiences and perceptions of subject guides. Courtois, Higgins and Kapur (2005) conducted an online survey posing the question "Was this guide helpful?" at the bottom of each of their guides to test the assumption that the significant amount of time and effort invested in creating guides resulted in guides that are beneficial to users. Most of the guide owners were discouraged by the results as $40 \%$ of respondents gave ratings of either "not helpful" or "a little helpful". However, several guide owners were inspired to improve their guides by addressing the issues that were raised in the surveys.

\section{Economics essay guides at UCT}

One of the biggest departments at the University of Cape Town, the School of Economics, reflected the following course enrolments in 2013:

- 1,351 students in Principles of Microeconomics (ECO1010F), a first-year, one-semester course that introduces students to the basic concepts of microeconomics, focusing on individual consumers and firms;

- 348 students in Macroeconomics 1 (ECO1011F), a first-year, one-semester course that introduces students to the basic concepts of macroeconomics, with a focus on the economy as a whole;

- 175 students in Microeconomics (ECO1110F), a one-semester course for students in the Education Development Unit; and,

- 923 students in Intermediate Microeconomics (ECO2003F), a second-year, one-semester course.

Students in each of these courses write an essay as a component of the course assessment. As part of essay writing support provided by the school, the Economics subject librarian creates essay guides using LibGuides, a commercial content management system. The aim of the guides is to help students find and use information effectively by providing:

- $\quad$ tips for effective search strategies;

- $\quad$ suggestions on relevant databases;

- instructions on accessing databases;

- links to other relevant sites on which students could search for information; and,

- guidance on referencing.

Figure 1 Screenshot of essay guide homepage for ECO1010F

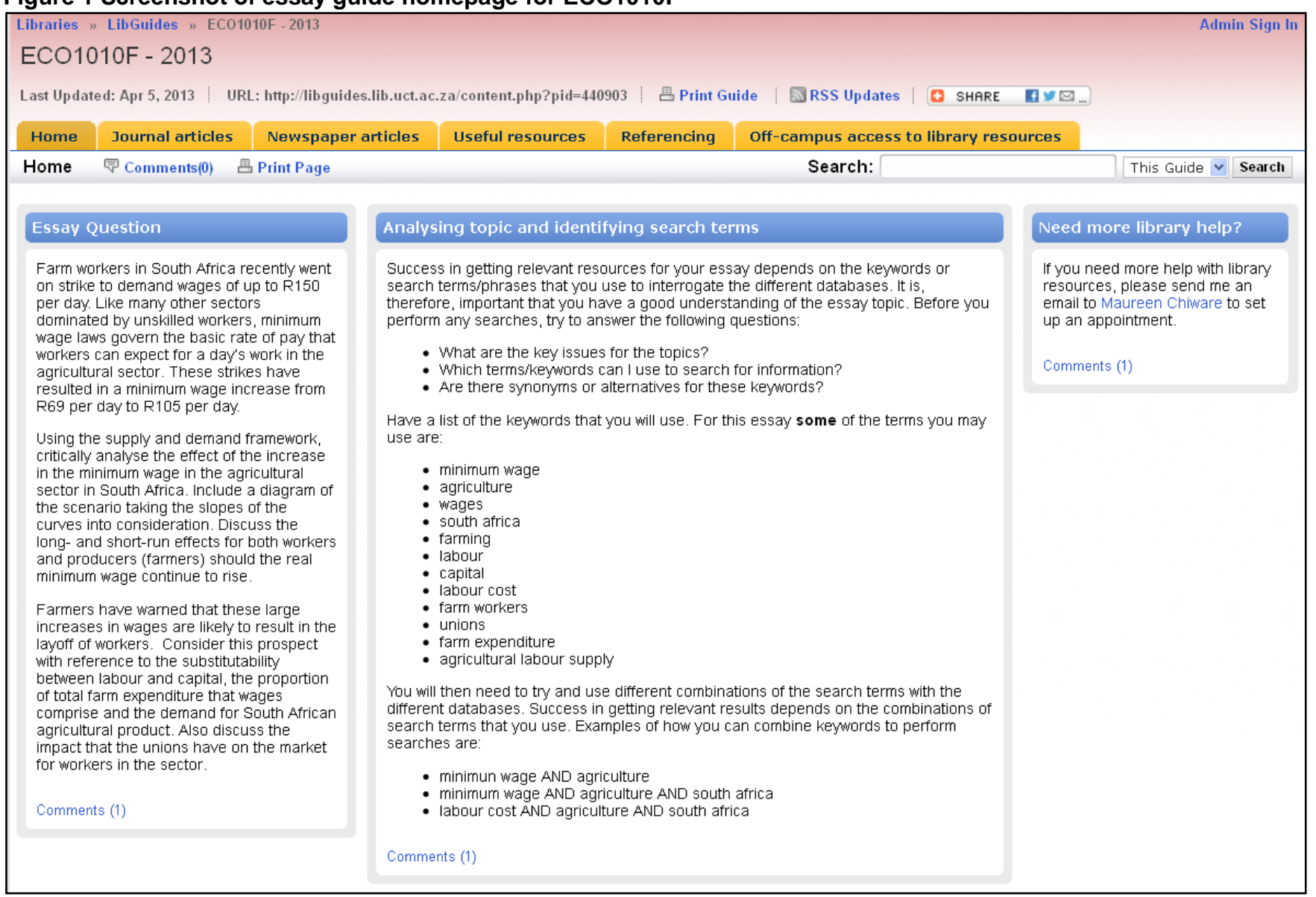


To facilitate the creation of the guides, the Economics subject librarian, who is the author of this paper and who has an interest in student information literacy, meets with the Writing Coordinator in the School of Economics to discuss the essay topics students will be given. This meeting ensures that the librarian has a good understanding of the topics as well as of what is expected of the students. The librarian makes a short presentation in Writing Workshops (run by the School of Economics) to introduce students to the LibGuides and to show them how to navigate the guides. Finding sufficient time to explain the guides during the Writing Workshops is difficult. Nevertheless, the librarian will continue to solicit timeslots in Writing Workshops as they provide a good opportunity to introduce the essay guides to the students. The librarian's close working relationship with the Writing Coordinator has been beneficial. In instances where the librarian could not be accommodated in Writing Workshops, the Writing Coordinator informed the students about the presence of the essay guides, provided contact details, and encouraged students to contact the librarian for help.

For the first semester of 2013, three essay guides were created for the four courses mentioned above. The essay topic for ECO1010F was the same as for ECO1110F; thus one guide was used for both courses. The guides, or subguides, resided within the Economics subject guide, linked to via tabs on the main guide. The three guides all used the template shown in Figure 1. The one difference was that the guide for ECO2003F did not have the tab for 'Useful Resources' because the students were expected to find any additional resources on their own. After the guides were published, email announcements were sent to students through the LMS, Vula, to alert them of the existence of the guides, and how to access them. The announcements also encouraged students to seek the assistance of the librarian if they required more help after consulting the guides. After a week, announcements were re-sent to students to remind them about the guides.

\subsection{Guide usage statistics}

As shown in Figure 2, there was a noticeable increase in the number of views that the Economics guide received after the essay guides were added to it.

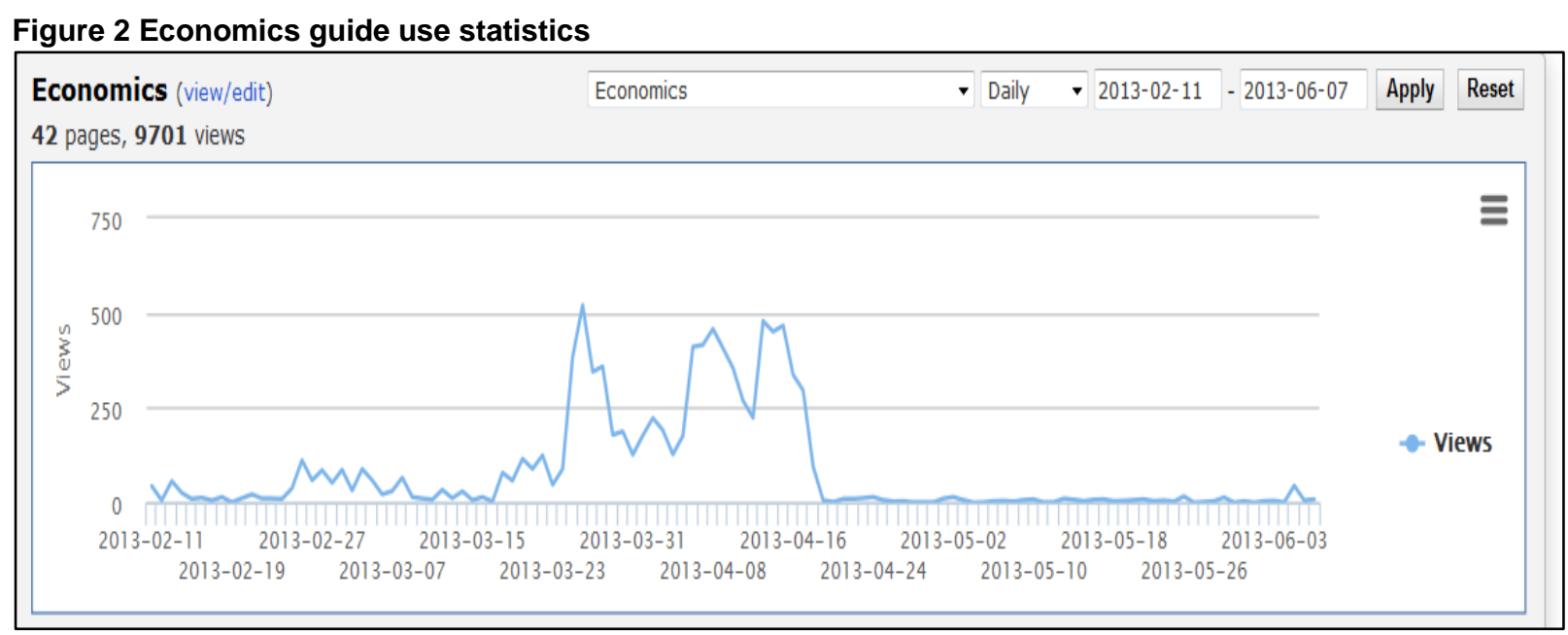

Source LibGuides 2013

The growth in guide usage started on 18 March 2013, the day the notification about the guides was sent to students. High usage of the guides was maintained until 18 April, the day the last student essay was due for submission. This pattern was observed in all three essay guides. The pattern is consistent with literature that supports the assertion that students prefer and will make more use of guides that are targeted, rather than general guides (Ouellette 2011; Yeo 2011; Courtois, Higgins \& Kapur 2005; Reeb \& Gibbons 2004). Similar to usage statistics of the Economics guide, Yeo (2011: 53) observed that the highest traffic on a course guide occurred when students were working on assignments.

The number of views each page received varied. After the homepage of the guides, the page with the highest number of views was the 'Useful Resources' page; possibly an indication that students prefer to be taken directly to resources rather than search for resources themselves. Ouellette's assertion that "students are busy and simply want to find articles for their assignments as quickly as possible" (2011: 444) seems to apply here. The number of views the guides received relative to the number of students registered for each course is shown in Table 1.

Table 1 Guide views

\begin{tabular}{cccc}
\hline Course & Number of students & Views & Views per student \\
\hline ECO1010F \& ECO1110F & 1,533 & 9,818 & 6 \\
ECO1011F & 349 & 2,129 & 6 \\
ECO2003F & 924 & 1,938 & 2 \\
\hline
\end{tabular}




\subsection{The evaluation}

The high usage of the guides was seen as a positive sign by the librarian, but usage statistics do not give any insight or feedback as to whether the students were using the guides effectively and successfully, or whether the students found the guides helpful. This exclusion motivated the librarian to conduct a survey to evaluate students' perceptions of the guides. The aim of the evaluation was broadly to determine how effective essay guides were in providing support to students. The evaluation thus set out to answer the following questions:

- How widely used were the Economics essay help guides?

- What are the students' perceptions of the usefulness of these guides?

- What improvements can be made to the guides?

An online questionnaire was designed using the evaluation component of the LMS, Vula, and sent to all students enrolled for the four courses. The questionnaire consisted of eight closed (seven for ECO2003F) and four open-ended questions. Students were asked:

- $\quad$ whether they had used the essay guides; and, if not, to provide reasons why;

- how they had found out about the guides;

- $\quad$ to rate each of the pages of the guide;

- to suggest measures to improve the guides.

Open-ended questions were included so that the responses could provide insight into the reasons why some students had not used the guides and how the guides could be improved. These responses helped the librarian identify areas in need of improvement.

\section{Findings and discussion}

Table 2 shows the response rate that was received to the questionnaire. The relatively high rate of response may have been a result of the evaluation running for four weeks, with weekly email reminders being sent.

Table 2 Response rate by course

\begin{tabular}{lcc}
\hline Course & Number of respondents & Response rate \\
\hline ECO1110F & 136 of 176 & $77 \%$ \\
ECO1011F & 168 of 349 & $48 \%$ \\
ECO1010F & 639 of 1,357 & $47 \%$ \\
ECO2003F & 360 of 924 & $39 \%$ \\
\hline
\end{tabular}

\subsection{Use of the essay guides}

More than $50 \%$ of respondents of all four courses reported to having used the guides (87\% for ECO1110F; $70 \%$ for ECO1010F; 67\% for ECO1011F; 54\% for ECO2003F). The librarian working with the Writing Coordinator and some of the lecturers may have contributed to the high usage of the guides. Staff in the faculty interact more with the students than does the librarian, so working with them can increase usage as "students will hear about library resources more often" (Barr 2010: 296) from people they trust. Results indicated that guide usage correlates with library instruction. Guide usage statistics show that the guides with the highest use (ECO1110F, ECO1010F and ECO1011F) were the same as those which were presented to the students by the librarian in the Writing Workshops. Furthermore, the class (ECO1110F) that had the highest proportion of students who attended the librarian's presentation also had the highest percentage of students that used the essay guide. Observations made at San Jose State University were that students who received library instruction made more use of subject guides than those who did not (Staley 2007: 129). Results reported by Yeo (2011) at Singapore Management University show a $49 \%$ increase in the usage of a course guide after the guide was used in a library training session.

\subsection{Awareness of the guides}

The results in Figure 3 show where students first heard about the guides. Vula, the LMS, and Writing Workshops are important platforms for interacting with students. Marketing of guides should, therefore, be focused in these spaces. In so doing, students do not have to leave their learning environments to learn about library resources.

\subsection{Non-use of the guides}

Figure 4 shows the responses of students to the question of why they had not used the guides. Similar to findings by Quellette (2011), a significant number of students reported that they simply felt they did not need them. 
Figure 3 Awareness of the guides
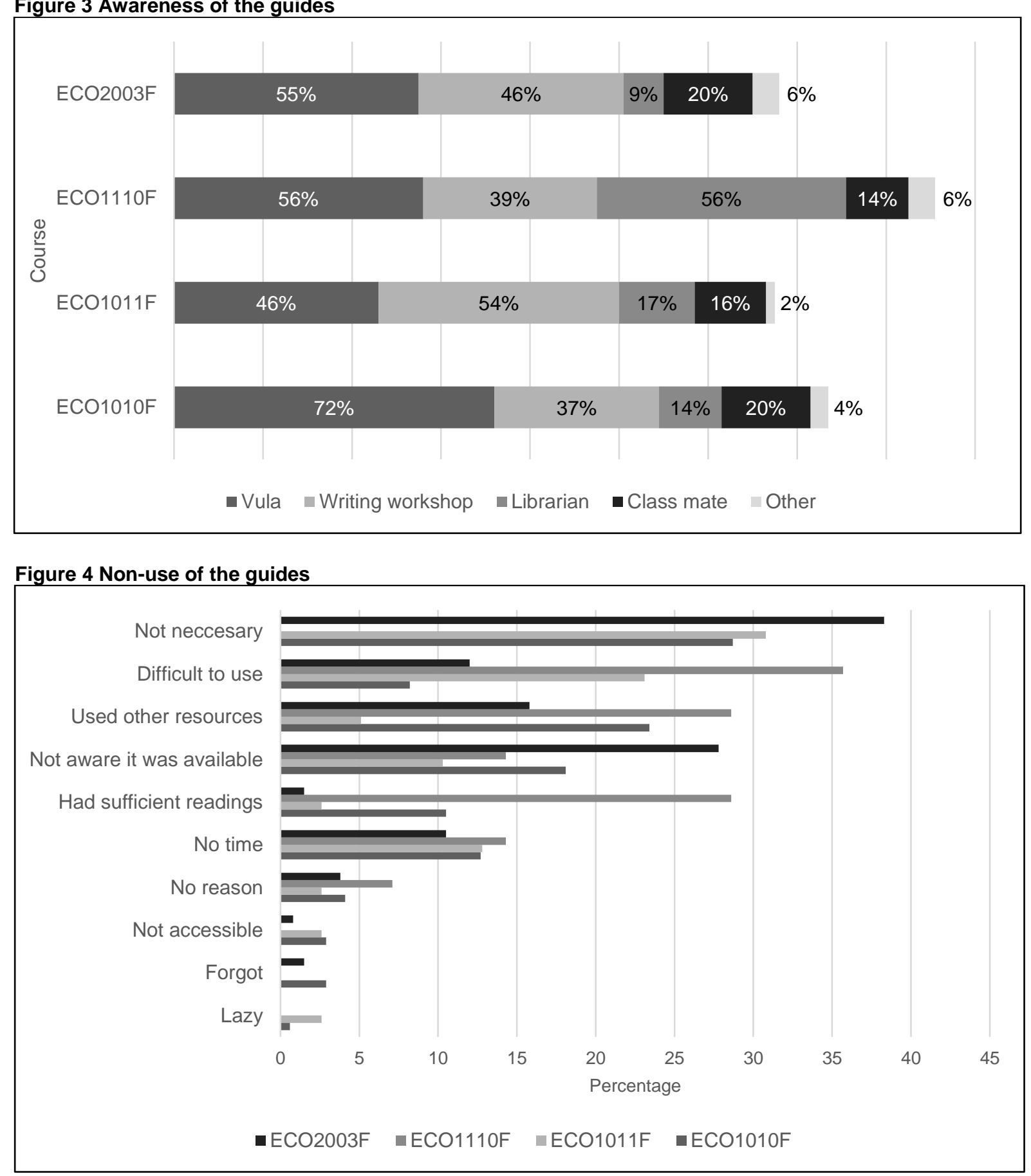

Of great concern is the proportion of students who thought that the guides were difficult to use. Similarly, of great concern is that another significant proportion of the respondents indicated that they were not aware the guides were available. Dalton and Pan (2014), Ouellette (2011) and Strutin (2008) found that a significant number of students in their studies did not know that subject guides existed. There is, therefore, need to increase and enhance the advertising and promotion of guides.

Some respondents suggested that the essay guides be made available through Vula, the LMS, which is not the case at present due to technological issues which should be resolved in future. Poor promotion and visibility of subject guides was noted by Tchangalova and Fiegley (2008) as possible contributors to users' lack of awareness and subsequent lack of use of guides. Therefore, having guides available through Vula will be a valuable way of making the guides visible. Guides can be further promoted by cataloguing them so that they are discoverable via the OPAC, as is the case at Li Ka Shing Library in Singapore (Yeo 2011: 58).

\subsection{Rating guide pages}

Students were asked to evaluate the pages of the guide on a rating scale of excellent, good, average, poor or very poor. Students could also indicate that they had not used the particular page. The ratings the guides received were generally 
positive. Table 3 shows the ratings that the guide pages received as an average percentage of the number of respondents for all four courses.

Table 3 Average rating of guide pages as a percentage of respondents

\begin{tabular}{ccccccc}
\hline Page & Excellent & Good & Average & Poor & Very poor & Did not use \\
\hline Topic analysis & 17 & 34 & 23 & 2 & 2 & 23 \\
How to find journal articles & 16 & 32 & 23 & 4 & 2 & 24 \\
How to find newspaper articles & 14 & 31 & 25 & 4 & 2 & 25 \\
Useful resources & 22 & 34 & 22 & 3 & 2 & 18 \\
Referencing & 25 & 27 & 20 & 5 & 2 & 22 \\
Off-campus login & 19 & 23 & 17 & 6 & 2 & 33 \\
\hline
\end{tabular}

\subsection{Improvement of the guides}

Figure 5 shows the suggestions that were made by the respondents as to how the guides could be improved, arranged in descending order with the suggestion made by the highest number of respondents at the top.

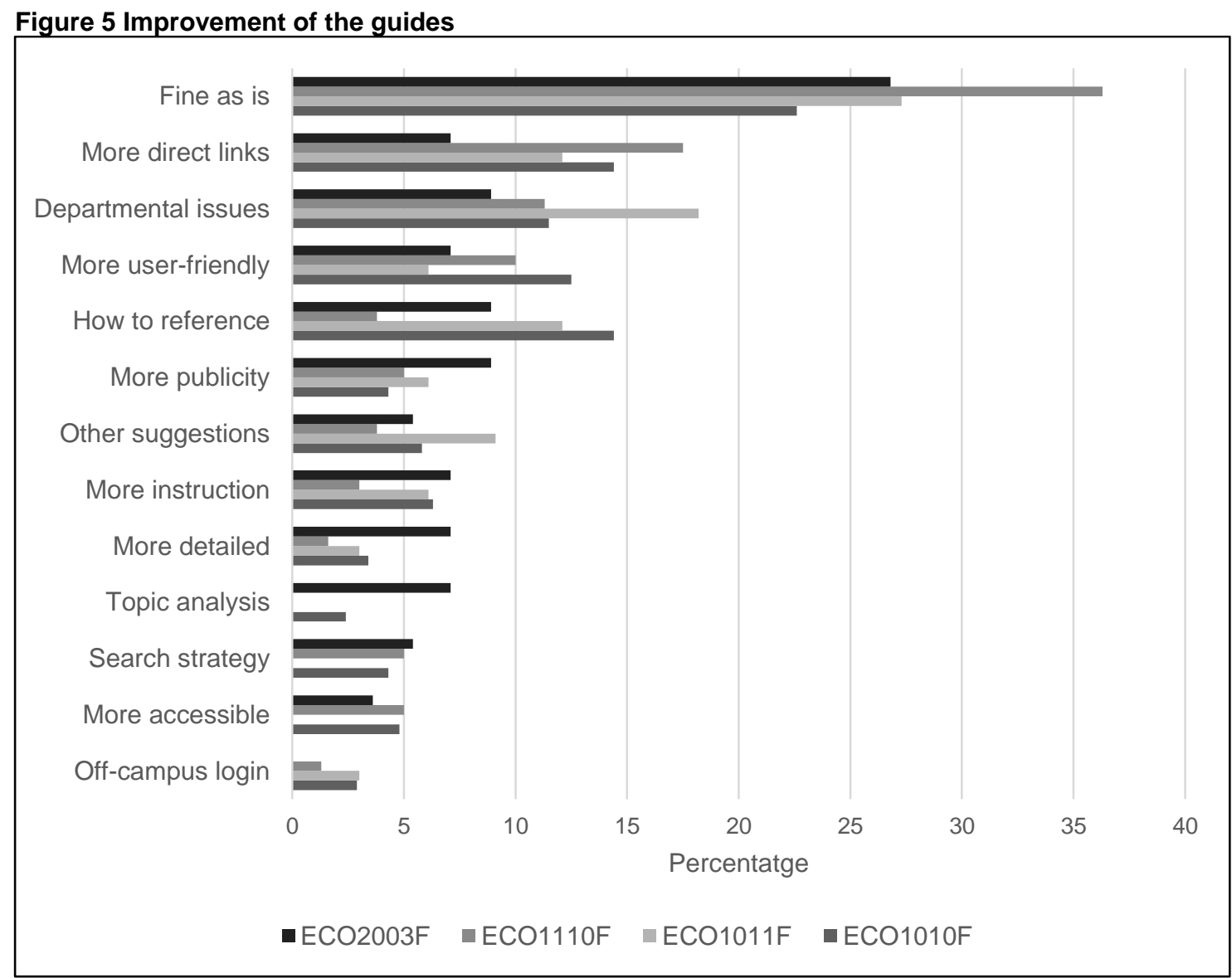

It was pleasing to note that at the top, a substantial proportion of respondents thought that the guides were 'fine' as they were and did not need any improvement. Of interest are the respondents who wanted more resources and direct links, echoing O'Sullivan and Scott's (2000) study results where some students wanted direct answers to their assignments. Meeting this need would be counterproductive as ultimately guides should teach students the skills to find scholarly resources for their essays themselves. In contrast, an interesting comment was that "the essay guide should supply fewer resources of research because it makes us, the students, lazy to do our own research and we become too dependent on it".

Some of the suggestions that were made did not relate to the library guide per se but were issues that needed to be referred to the School of Economics, for example the need for:

- more one-on-one meetings with tutors;

- help with the structure of the essay;

- more essay lectures and workshops; 
- examples of good essays; and,

- $\quad$ more tutors.

Some students thought that the guides were complicated and needed to be explained. Their answers corresponded to verbal reports from some students during consultations with the librarian. The students explained that they did not know what to do when they found themselves on the homepage of the guides. It became apparent that there had been an oversight in not including an explanation on the guides of what they were and how they should be accessed. The solution, as both Brazzeal (2006) and Courtois, Higgins and Kapur (2005) suggest, is to incorporate a welcome and introductory message, providing a clear description of the purpose of the guides and how they can be used.

Referencing seemed to be a problem with some students. Consequently, more support for correct referencing would need to be included in the guide. Marks are deducted for not referencing properly, so students are keen to avoid penalties for incorrect referencing. This problem has been addressed by introducing a referencing workshop facilitated by the Writing Centre of the university. There were additional recommendations in the feedback that included, for example, the suggestion that including a chat room and instructional videos would be useful and that all the links are checked regularly.

\subsection{Other comments on the guides}

Feedback indicated that the majority of those surveyed were grateful for the guides and noted that the guides had been very helpful, as shown in Figure 6.

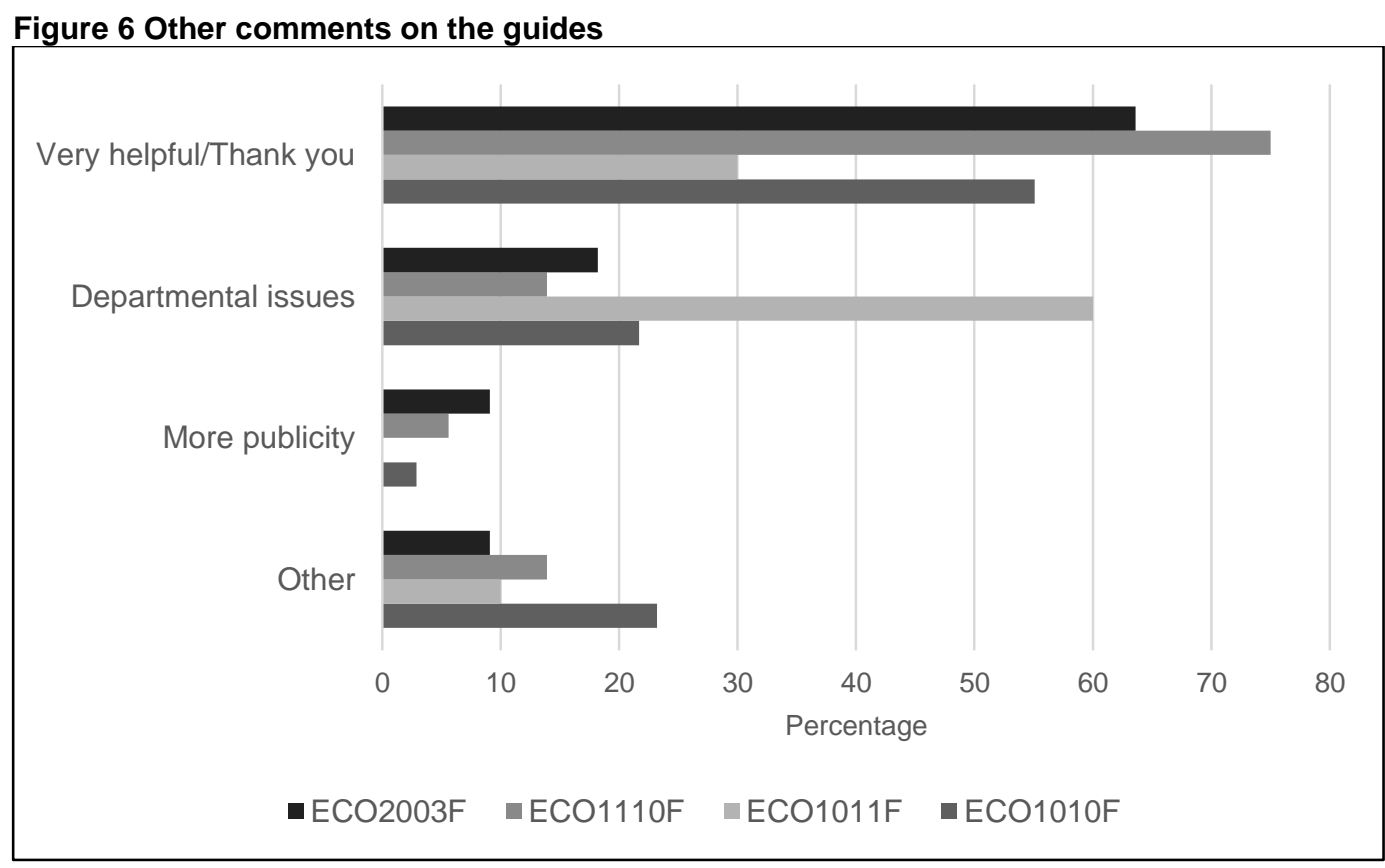

The following are a few comments that reflect the students' overall satisfaction with the guides and their compliments to the librarian:

- "The library guide is extremely helpful in essay writing. It personally assisted me immensely, and I am certain I will consult it again in the near future."

- "Great job by the librarian. Everything I used in my essay I got from the suggested sources. I am pleased with my mark too!"

- "It helped a lot and finding needed information was really easy!!"

- "We are lucky to have such assistance. Thanks for the good work."

- "Thank you for the thought of compiling such a tool for me as a first year whom until I used the library guide, wouldn't have been able to do my essay and submit in time."

Results of the survey were shared with the Writing Coordinator as nearly $20 \%$ of the suggestions for improvement made by the students would need the attention of the Writing Coordinator and the School of Economics.

\section{Conclusion}

This assessment of essay guides has been enlightening. In line with the conclusions drawn by a number of other authors (Leighton \& May 2013; Ouellette 2011; Yeo 2011; Adebonojo 2010; Gonzalez \& Westbrock 2010; Strutin 2008), the students used essay guides more than they used the general Economics guide as indicated by the guide usage statistics as well as their responses in the survey. Survey results showed that a large proportion of the students were of the opinion that the guides had been helpful and they expressed their appreciation to the librarian for having created the guides. Two 
main issues that would need attention for future guides are making them accessible on Vula and improving the ease of use of the guides.

Although creating assignment or course-specific guides is time consuming, the substantial usage rates as well as the positive feedback received make it well worth the effort. In addition, the existence of essay guides helped to reduce the amount of time the librarian spent consulting with students, as the guides provided a ready-made and standard way of responding to the numerous queries from students. The author plans to use the feedback from the survey to implement changes to guides in the future. Initial changes that have been made to guides include an introduction that explains what the guide is for and how to navigate it. Future research could investigate if there is any correlation between guide use and students' marks.

\section{References}

Adebonojo, L.D. 2010. LibGuides: customizing subject guides for individual courses. College \& Undergraduate Libraries, 17: 398-412. DOI:10.1080/10691316.2010.525426.

Barr, D. 2010. Reaching students where they go: embedding library resources in course content. Science \& Technology Libraries, 29(4): 289-297. DOI:10.1080/0194262X.2010.523305.

Bowen, A. 2012. A LibGuides presence in a Blackboard environment. Reference Services Review, 40(3): 449-468. DOI:10.1108/00907321211254698.

Brazzeal, B. 2006. Research guides as library instruction tools. Reference Services Review, 34(3): 358-367. DOI:10.1108/00907320610685319.

Courtois, M.P., Higgins, M.E. and Kapur, A. 2005. Was this guide helpful? Users' perceptions of subject guides. Reference Services Review, 33(2): 188-196. DOI:10.1108/00907320510597381.

Dalton, M. and Pan, R. 2014. Snakes or ladders? Evaluating a LibGuides pilot at UCD Library. The Journal of Academic Librarianship, 40: 515-520. DOI:10.1016/j.acalib.2014.05.006.

Gonzalez, A.C. and Westbrock, T. 2010. Reaching out with LibGuides: establishing a working set of best practices. Journal of Library Administration, 50: 638-656. DOI:10.1080/01930826.2010.488941.

Leighton, H.V. and May, D. 2013. The library course page and instruction: perceived helpfulness and use among students. Internet Reference Service Quarterly, 18(2): 127-138. DOI:10.1080/10875301.2013.804019.

Murphy, S.A. and Black, E.L. 2013. Embedding guides where students learn: do design choices and librarian behavior make a difference? The Journal of Academic Librarianship, 39(6): 528-534. DOI:10.1016/j.acalib.2013.06.007.

O'Sullivan, M.K. and Scott, T.J. 2000. Pathfinders go online. Library Journal, 125(10): 40-42.

Ouellette, D. 2011. Subject guides in academic libraries: a user-centred study of uses and perceptions. Canadian Journal of Information \& Library Sciences, 35(4): 436-451.

Reeb, B. and Gibbons, S.L. 2004. Students, librarians and subject guides: improving a poor rate of return. Portal: libraries and the academy, 4(1): 123-130. DOI:10.1353/pla.2004.0020.

Staley, S. M. 2007. Academic subject guides: a case study of use at San Jose State University. College \& Research Libraries, 68(2): 119-140. Available: http://crl.acrl.org/content/68/2/119.full.pdf+html (14 October 2014).

Strutin, M. 2008. Making research guides more useful and more well used. Issues in Science and Technology Librarianship, 55. DOI:10.5062/F4M61H5K.

Tchangalova, N. and Fiegley, A. 2008. Subject guides: putting a new spin on an old concept. Electronic Journal of Academic and Special Librarianship, 9(3). Available: http://hdl.handle.net/1903/14751 (10 September 2014).

Wakeham, M., Roberts, A., Shelley, J., and Wells, P. 2012. Library subject guides: a case study of evidence-informed library development. Journal of Librarianship and Information Science, 44(3): 199-207. DOI:10.1177/0961000611434757.

Yeo, P. P. 2011. High yields from course guides at Li Ka Shing Library. Singapore Journal of Library and Information Management, 40: 50-64. Available: http://ink.library.smu.edu.sg/library_research/14/ (11 October 2014).

The author would like to thank Associate Professor Karin de Jager for her invaluable comments and guidance, Seta Jackson for her assistance with the evaluations, and would like to acknowledge Lara Skelly who created the initial essay guides. 